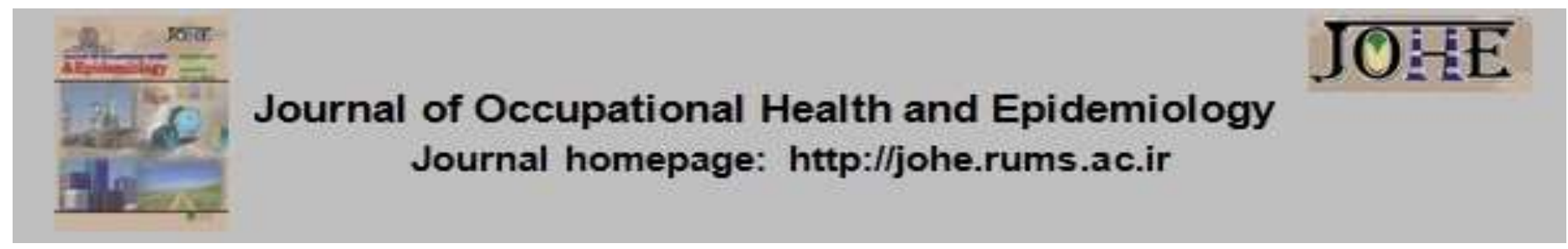

\title{
Prevalence and Determinants of Hypertension among Iranian Taxi Drivers (2018)
}

\author{
Payam Khanlari ${ }^{1}$, Masoud Khosravipour ${ }^{*}$, Faramarz Gharagozlou ${ }^{3}$, Rashid Heidarimoghadam ${ }^{4}$, \\ Mohammad Babamiri ${ }^{5}$ \\ 1- MSc Student, Student Research Committee, Hamadan University of Medical Sciences, Hamadan, Iran. \\ 2- MSc Student, Student Research Committee, Kermanshah University of Medical Sciences, Kermanshah, Iran. \\ 3- Assistant Prof., Dept. of Occupational Health Engineering, School of Health, Kermanshah University of Medical Sciences, \\ Kermanshah, Iran. \\ 4- Professor, Dept. of Ergonomics, School of Health, Hamadan University of Medical Sciences, Hamadan, Iran. \\ 5- Assistant Prof., Dept. of Ergonomics, School of Health, Hamadan University of Medical Sciences, Hamadan, Iran.
}

\section{Article Info}

* Corresponding author:

Masoud Khosravipour,

E-mail:

masoudkhosravipour74@

gmail.com

\section{Article history}

Received: Jan 2020

Accepted: Aug 2020

10.29252/johe.9.1.1

Print ISSN: 2251-8096 Online ISSN: 2252-0902

Peer review under responsibility of Journal of Occupational Health and Epidemiology
Citation: Khanlari P, Khosravipour M, Gharagozlou F, Heidarimoghadam R, Babamiri M. Prevalence and Determinants of Hypertension among Iranian Taxi Drivers in 2018. JOHE 2020; 9(1):1-9.

\begin{abstract}
Background: The prevalence of hypertension (HTN) among Iranian taxi drivers has not been well defined. This study aimed to determine the prevalence of HTN and to identify factors influencing its prevalence among Iranian taxi drivers in 2018.

Materials and Methods: This cross-sectional study was conducted on a total sample of 321 taxi drivers in Kermanshah province in 2018. The participants were classified into two groups, including the HTN group (SBP $\geq 140$ or DBP $\geq 90$ ) and the non-HTN group (SBP $<140$ or DBP $<90$ ). A self-administrated questionnaire, including questions about demographic information, medical history, and work-related factors was employed to collect data.

Results: According to the observations, 59.8\% of the participants (192/321) suffered from HTN. According to the adjusted logistic regression model and the per one unit increase, there was significantly higher odds of HTN for age (odds ratio [OR] $=1.04$ and $95 \%$ confidence interval $[\mathrm{Cl}]=1.02,1.06)$ and work history $(\mathrm{OR}=1.08$ and $95 \% \mathrm{Cl}=1.03$, $1.13)$; in contrast, there was a lower risk of HTN for sleep duration (OR=0.83 and $95 \%$ $\mathrm{Cl}=0.69,0.99)$ and Work Days Per Week (WDPW) (OR=0.73 and 95\% $\mathrm{Cl}=0.57,0.94)$. In the categorical analysis, a significantly higher risk of HTN was observed in the drivers with age $\geq 45$, work history $\geq 5$, Work Hours Per Day (WHPD) $>10$, WDPW $\leq 6$, married, and poor economic status $\leq$ a 2-million Toman income per month.

Conclusions: This study introduces taxi drivers as a high-risk HTN group in the society. Hence, they should be informed of HTN risk factors and undergo regular checkups.
\end{abstract}

Keywords: Hypertension, Cardiovascular Diseases, Risk Factors, Iran.

\section{Introduction}

Hypertension (HTN) is well established as the most common chronic disease worldwide. It is predicted that the total number of hypertensive patients will rise from 972 million individuals in 2000 to 1.56 million individuals in 2025 [1]. Since HTN is asymptomatic in acute stages, the morbidity and mortality resulting from it could be dramatically high [2]. Approximately $47 \%$ of ischemic heart diseases and $57 \%$ of stroke cases, being among the prime causes of death in the world, are related to HTN [3-5]. Besides, about 9.5 million annual deaths (16.5\% of the total deaths) are attributed to HTN [6]. It was observed that the incidence and mortality of kidney diseases caused by $\mathrm{HTN}$ in 2007 and 2017 significantly increased by $28 \%$ and $41.4 \%$, respectively [5, 7]. Hence, 
identification of high-risk subjects and risk factors affecting HTN prevalence is a high priority.

Professional driving puts drivers under stressful conditions, such as a sedentary lifestyle, an unhealthy diet plan, irregular work schedules [810], external stressors, such as noise [11], vibration [12], air pollution [13, 14], and toxic vehicle exhaust emissions [15]. Exposure to these factors turns professional drivers, including bus, truck, and taxi drivers, into high-risk groups for cardiovascular diseases (CVDs). In the past few decades, some studies investigated CVDs among professional drivers. The results of a cohort study, which investigated hospital admissions among professional drivers in Denmark, indicated that age-standardized hospital admissions ratios (SHRs) for CVDs, including ischemic heart disease, myocardial infarction, and cerebrovascular disease, were significantly higher in male taxi and bus drivers than in other drivers [16]. Another study indicated a stronger risk of myocardial infarction among drivers [17]. Furthermore, in another study, a higher risk of stroke was reported in drivers than in the general population [18]. Similarly, in a series of other studies which investigated cardiovascular risk factors, greater risks of metabolic syndrome [1922], poor sleep quantity and quality [23-26], as well as HTN [27-36] were reported among professional drivers.

Up until now, although many studies have investigated the prevalence of HTN among professional drivers, including bus and truck drivers, little evidence exists on investigating the prevalence of HTN among taxi drivers. In addition, few studies have examined the risk factors influencing the prevalence of HTN among drivers, and in particular, among taxi drivers. To the best of our knowledge, no study has investigated this association among Iranian taxi drivers. Therefore, this study aims to fill this gap by determining the prevalence of HTN and identifying its determinants among Iranian taxi drivers.

\section{Materials and Methods}

This cross-sectional study was carried out in Kermanshah province located in western Iran in 2018 in the three months of spring to early summer. Multistage sampling was used to select the study participants. To this end, Kermanshah province was divided into the five central, western, eastern, southern, and northern areas (strata). Next, a similar number of participants were selected from each study area (about 74 drivers in each area). We determined the sample size according to formula 1 as follows:
[1]

$$
n=\frac{z^{2} p(1-p)}{d^{2}}
$$

Where $n$ indicates the required sample size at the $95 \%$ level of significance, $p$ represents the prevalence of HTN among the taxi drivers, which is set at 0.4 according to the previous studies $[8,27$, 29-30, 38-41], and $d$ is the degree of precision set at 0.05 . Accordingly, the sample size consisted of 369 subjects. In the present study, we only included male taxi drivers licensed by the Taxi Organization, so private taxi drivers were not included. After data collection, taxi drivers with less than a one-year work experience were excluded. In the end, the data obtained from 321 taxi drivers were analyzed.

For the purpose of data collection, a two part selfadministrated questionnaire, including questions about demographic information and work-related factors, was employed. Demographic data included age, height, weight, marital status (married or single), current smoking habits, education levels (high school diplomas, lower degrees, and university degrees), economic status (poor status was $\leq$ a 2-million Toman income per month, medium status was between a 2- and a 3million Toman income per month, and good status was $>$ a 3-million Toman income per month), as well as self-reported diseases and familial medical history. Besides, work-related factors included work experience, work hours per day (WHPD), work days per week (WDPW), self-reported fatigue (SRF), and sleep duration. We used an analog scale for measuring SRF, which ranged from 0 (no fatigue) to 100 (the highest level of fatigue). Sleep duration was determined for each subject by questions "at what hours at night did you usually go to sleep and at what hours did you wake up in the past months?" Moreover, a body mass index (BMI) was calculated for each participant via dividing weight $(\mathrm{kg})$ by height $(\mathrm{m} 2)$. In addition, the participants' blood pressure was measured by a Beurer BC16 Blood Pressure Monitor according to the standard protocol [37]. In this study, HTN was defined as systolic blood pressure (SBP) $\geq 140$ $\mathrm{mmHg}$ or diastolic blood pressure (DBP) $\geq 90$ $\mathrm{mmHg}$, according to the latest definition provided by the European Society of Cardiology/the European Society of Hypertension (ESC/ESH) [37]. It is worth noting, to minimize the measurement errors, blood pressure was measured again at a 10-minute interval for each participant, with the average blood pressure computed and recorded in the end.

After importing the data to SPSS software version 25 and classifying them, the normality of the distribution of the quantitative variables was determined by the Shapiro-Wilk test. Accordingly, 
the Mann-Whitney test was utilized to assess the significance of the difference between the study groups. In addition, to investigate the significant difference between the study groups for nominal variables, the Chi-square test was utilized. In this study, quantitative and nominal variables were represented by means (the standard deviation) and numbers (percentages). In addition, logistic regression was utilized to examine the effects of study variables on the risk of HTN. Besides, logistic regression was presented by the odds ratio $(\mathrm{OR})$ at a $95 \%$ confidence interval $(\mathrm{Cl})$ for both unadjusted and adjusted models. It is worth noting that the Spearman's correlation coefficient was employed to examine correlations between the study variables before including them in the model. Moreover, in the adjusted logistic regression model, those variables were considered, which were significantly different among the study groups, or which had a significant association with HTN ( $p$-value < 0.10) in the simple logistic regression.

\section{Results}

According to the study results, $59.8 \%$ of the participants (192/321) suffered from HTN. The summary of the study groups' characteristics, including demographic data, work-related factors, as well as self and family medical histories have been provided in Table 1. The results indicate a significant difference between the two groups only in the variables of age, work history, WDPW, marital status, education levels, and self-reported economic status $(p<0.05)$.

Table 1. The summary of the characteristics of the included taxi drivers, Kermanshah province, 2018

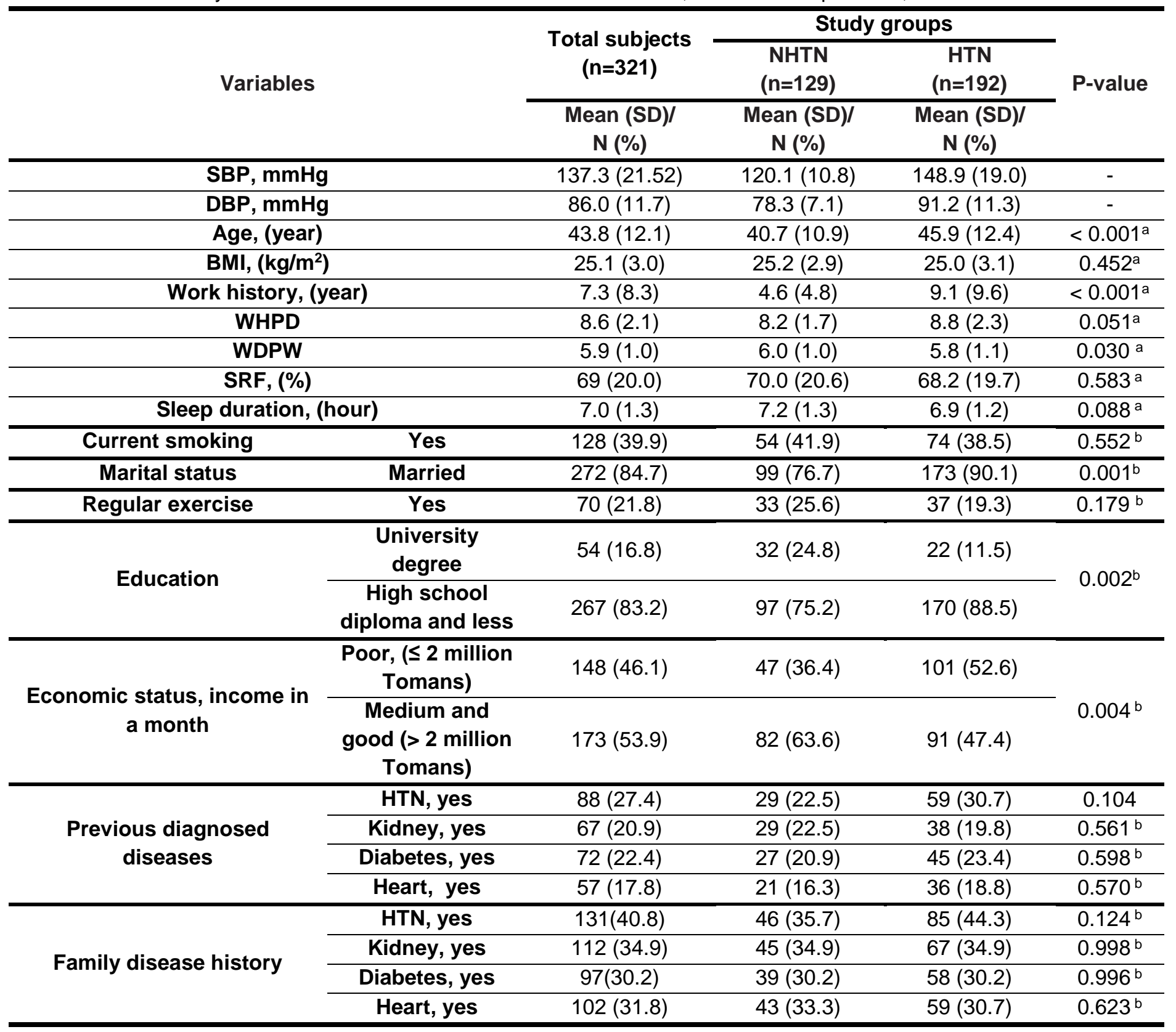

Abbreviations: HTN: hypertension; NHTN: non-hypertensive; SD: standard deviation; N, number; BMI: body mass index; WHPD: work hours per day; WDPW: work days per week; SRF: self-reported fatigue; SBP: systolic blood pressure; DBP: diastolic blood pressure a Mann-Whitney test for the difference between the two groups; $b$ Chi-square test for the difference between the two groups; A difference is significant at $\mathrm{p}$-value $<0.05$. 
The results of the logistic regression are presented in Table 2. In both adjusted and unadjusted models, it was observed that the subjects aged $\geq$ 45 years, married, and with poor economic status had a significantly higher risk of HTN than their reference group. In addition, in terms of the variable of educational level, there was a significantly higher risk of HTN in the subjects with a high school diploma and less, than the reference group in the unadjusted model at $p$-value $<0.05$ and in the adjusted model at $p$-value $<0.10$.

Table 2. The logistic regression models for hypertension in the included taxi drivers according to demographic and medical history data, Kermanshah province, 2018

\begin{tabular}{|c|c|c|c|c|c|c|}
\hline \multirow{3}{*}{\multicolumn{2}{|c|}{ Variables }} & \multirow{3}{*}{$\begin{array}{c}\text { No (\%) } \\
\text { HTN/NHTN }\end{array}$} & \multicolumn{4}{|c|}{ Logistic regression models } \\
\hline & & & \multicolumn{2}{|l|}{ Simple } & \multicolumn{2}{|l|}{ Multiple } \\
\hline & & & OR $(95 \% \mathrm{Cl})$ & $\begin{array}{c}\mathrm{p}- \\
\text { value }\end{array}$ & OR $(95 \% \mathrm{Cl})$ & $\begin{array}{c}p- \\
\text { value }\end{array}$ \\
\hline \multirow{2}{*}{ Age $^{a}$} & $<45$ & $97(50.5) / 82(63.6)$ & Referent & - & Referent & - \\
\hline & $\geq 45$ & $95(49.5) / 47(36.4)$ & $1.71(1.08,2.70)$ & 0.022 & $1.68(1.04,2.76)$ & 0.035 \\
\hline \multirow{2}{*}{$\mathrm{BMI}^{\mathrm{b}}$} & $<25$ & $59(41.3) / 70(39.3)$ & Referent & - & Referent & - \\
\hline & $\geq 25$ & $84(58.7) / 108(60.7)$ & $0.92(0.59,1.44)$ & 0.726 & $0.90(0.56,1.46)$ & 0.672 \\
\hline \multirow{2}{*}{ Marital status $^{a}$} & Single & $19(38.8) / 30(61.2)$ & Referent & - & Referent & - \\
\hline & Married & $173(63.3) / 99(36.4)$ & $2.76(1.48,5.16)$ & 0.001 & $2.57(1.32,5.01)$ & 0.006 \\
\hline \multirow{2}{*}{$\begin{array}{c}\text { Regular } \\
\text { exercise }^{b}\end{array}$} & Yes & $37(52.9) / 33(47.1)$ & Referent & - & Referent & - \\
\hline & No & $155(61.8) / 96(38.2)$ & $1.44(0.84,2.46)$ & 0.181 & $1.21(0.68,2.15)$ & 0.517 \\
\hline \multirow{2}{*}{$\underset{b}{\text { Smoking habit }}$} & No & $118(61.1) / 75(38.9)$ & Referent & - & Referent & - \\
\hline & Yes & $74(57.8) / 54(42.2)$ & $0.87(0.55,1.37)$ & 0.552 & $0.91(0.56,1.47)$ & 0.685 \\
\hline \multirow{2}{*}{$\begin{array}{c}\text { Education } \\
\text { level }^{c}\end{array}$} & University & $22(11.5) / 32(24.8)$ & Referent & - & Referent & - \\
\hline & $\begin{array}{c}\text { High school } \\
\text { diploma and less }\end{array}$ & $170(88.5) / 97(75.2)$ & $2.55(1.40,4.63)$ & 0.002 & $1.73(0.92,3.28)$ & 0.092 \\
\hline \multirow{2}{*}{$\begin{array}{l}\text { Economic } \\
\text { status }^{b}\end{array}$} & Good & $91(47.4) / 82(63.6)$ & Referent & - & Referent & - \\
\hline & Poor & $101(52.6) / 47(36.4)$ & $1.94(1.23,3.06)$ & 0.005 & $1.72(1.07,2.78)$ & 0.026 \\
\hline \multicolumn{7}{|l|}{$\begin{array}{c}\text { Previous } \\
\text { diagnosed } \\
\text { disease }^{b}\end{array}$} \\
\hline \multirow{2}{*}{ HTN } & No & $133(69.3) / 100(77.5)$ & Referent & - & Referent & - \\
\hline & Yes & $59(30.7) / 29(22.5)$ & $1.53(0.91,2.56)$ & 0.105 & $1.35(0.77,2.37)$ & 0.293 \\
\hline \multirow{2}{*}{ Kidney } & No & $154(60.6) / 100(39.4)$ & Referent & - & Referent & - \\
\hline & Yes & $38(56.7) / 29(43.3)$ & $0.85(0.49,1.47)$ & 0.561 & $0.78(0.44,1.39)$ & 0.395 \\
\hline \multirow{2}{*}{ Diabetes } & No & $147(59.0) / 102(41.0)$ & Referent & - & Referent & - \\
\hline & Yes & $45(62.5) / 27(37.5)$ & $1.16(0.67,1.98)$ & 0.598 & $0.90(0.50,1.61)$ & 0.713 \\
\hline \multirow{2}{*}{ Heart } & No & $156(59.1) / 108(40.9)$ & Referent & - & Referent & - \\
\hline & Yes & $36(63.2) / 21(36.8)$ & $1.19(0.66,2.14)$ & 0.570 & $1.18(0.62,2.24)$ & 0.610 \\
\hline \multicolumn{7}{|l|}{$\begin{array}{c}\text { Family medical } \\
\text { history }^{\mathrm{b}}\end{array}$} \\
\hline \multirow{2}{*}{ HTN } & No & $107(56.3) / 83(43.7)$ & Referent & - & Referent & - \\
\hline & Yes & $85(64.9) / 46(35.1)$ & $1.43(0.91,2.67)$ & 0.124 & $1.19(0.72,1.94)$ & 0.499 \\
\hline \multirow{2}{*}{ Kidney } & No & $125(59.8) / 84(40.2)$ & Referent & - & Referent & - \\
\hline & Yes & $67(59.8) / 45(40.2)$ & $1.00(0.63,1.60)$ & 0.998 & $0.83(0.50,1.38)$ & 0.471 \\
\hline \multirow{2}{*}{ Diabetes } & No & $134(59.8) / 90(40.2)$ & Referent & - & Referent & - \\
\hline & Yes & $58(59.8) / 39(40.2)$ & $1.00(0.61,1.62)$ & 0.996 & $0.88(0.52,1.48)$ & 0.627 \\
\hline \multirow{2}{*}{ Heart } & No & $133(60.7) / 86(39.3)$ & Referent & - & Referent & - \\
\hline & Yes & $59(57.8) / 43(42.2)$ & $0.89(0.55,1.43)$ & 0.623 & $0.75(0.45,1.25)$ & 0.264 \\
\hline
\end{tabular}

Abbreviations: HTN: hypertension; NHTN: non-hypertensive; OR: odds ratio; Cl: confidence interval; BMI: body mass index

a WHPD, WDPW, sleep duration, and economic status

${ }^{b}$ WHPD, WDPW, sleep duration, economic status, and age

c WHPD, WDPW, sleep duration, economic status, and work history

An association is significant at $p$-value $<0.05$.

The effects of work-related factors, including work history, WHPD, WDPW, SRF, and sleep duration on the risk of HTN have been presented in Table
3. We observed that drivers with a 5-year experience and higher who worked 10 hours and more per day had a significantly higher risk of HTN 
than the reference group. Interestingly, there was a lower risk of HTN in the subjects who worked 7 days per week than those who worked 6 days and less per week.

Table 3. The logistic regression models for hypertension in the included taxi drivers according to work-related factors, Kermanshah province, 2018

\begin{tabular}{|c|c|c|c|c|c|c|}
\hline \multirow{3}{*}{ Variables } & & \multirow{3}{*}{$\begin{array}{c}\text { No (\%) } \\
\text { HTN vs. NHTN }\end{array}$} & \multicolumn{4}{|c|}{ Logistic regression models } \\
\hline & & & \multicolumn{2}{|c|}{ Simple } & \multicolumn{2}{|c|}{ Multiple } \\
\hline & & & OR $(95 \% \mathrm{Cl})$ & P-value & OR $(95 \% \mathrm{Cl})$ & P-value \\
\hline \multirow{2}{*}{ Work history $^{a}$} & $<5$ & $84(43.8) / 89(69.0)$ & Referent & - & Referent & - \\
\hline & $\geq 5$ & $108(56.3) / 40(31.0)$ & $2.86(1.79,4.58)$ & $<0.001$ & $2.20(1.34,3.63)$ & 0.002 \\
\hline \multirow{3}{*}{ WHPD ${ }^{b}$} & $\leq 8$ & $97(50.5) / 75(58.1)$ & Referent & - & Referent & - \\
\hline & $9-10$ & $65(33.9) / 47(36.4)$ & $1.08(0.66,1.73)$ & 0.785 & $1.08(0.65,1.81)$ & 0.763 \\
\hline & $\geq 10$ & $30(15.6) / 7(5.4)$ & $3.31(1.38,7.96)$ & 0.007 & $2.64(1.02,6.81)$ & 0.045 \\
\hline \multirow{2}{*}{ WDPW c } & $\leq 6$ & 134(69.8)/77(59.7) & Referent & - & Referent & - \\
\hline & 7 & $58(30.2) / 52(40.3)$ & $0.64(0.40,1.23)$ & 0.062 & $0.55(0.33,0.90)$ & 0.018 \\
\hline \multirow{2}{*}{ SRF ${ }^{d}$} & $<60$ & $78(40.6) / 58(45.0)$ & Referent & - & Referent & - \\
\hline & $\geq 60$ & $114(59.4) / 71(55.0)$ & $1.19(0.76,1.87)$ & 0.441 & $1.23(0.76,1.99)$ & 0.390 \\
\hline \multirow{2}{*}{ Sleep duration ${ }^{d}$} & $\geq 7$ & $69(35.9) / 39(30.2)$ & Referent & - & Referent & - \\
\hline & $\leq 6$ & $123(64.1) / 90(69.8)$ & $1.30(0.80,2.09)$ & 0.289 & $1.43(0.86,2.38)$ & 0.167 \\
\hline
\end{tabular}

Abbreviations: HTN: hypertension; NHTN: non-hypertensive; OR: odds ratio; Cl: confidence interval; BMI: body mass index; WHPD: work hours per day; WDPW: work days per week; SRF: self-reported fatigue; HTN: hypertension; NBP: normal blood pressure a WHPD, WDPW, sleep duration, economic status, and education levels

bWDPW, sleep duration, economic status, and age

c WHPD, sleep duration, economic status, and age

${ }^{d}$ WHPD, WDPW, sleep duration, economic status, and age

An association is significant at $p$-value $<0.05$.

Table 4 shows the unadjusted and adjusted logistic regression models for the estimation of the risk of HTN in the case of per unit increase in the quantitative variables. In both models, upon a oneyear increase in the work history, the risk of HTN increased significantly. However, it was observed that upon a one-day increase in WDPW, the risk of HTN decreased significantly in both models.
According to the unadjusted model, there was a significantly higher risk of HTN in terms of the variables of WHPD and sleep duration. In contrast, in accordance with the adjusted model, the risk was significant at $p<0.10$. In terms of other variables, including $\mathrm{BMI}$ and SRF, no significant association was observed.

Table 4. The logistic regression models for hypertension per 1 -fold increase in the quantitative variables among taxi drivers, Kermanshah province, 2018

\begin{tabular}{|c|c|c|c|c|}
\hline \multirow{3}{*}{ Variables } & \multicolumn{4}{|c|}{ Logistic regression models } \\
\hline & \multicolumn{2}{|c|}{ Simple } & \multicolumn{2}{|c|}{ Multiple } \\
\hline & OR (95\% Cl) & p-value & OR $(95 \% \mathrm{Cl})$ & p-value \\
\hline Age $^{\mathrm{a}}$ & $1.04(1.02,1.06)$ & $<0.001$ & $1.04(1.02,1.06)$ & 0.001 \\
\hline $\mathrm{BMI}^{\mathrm{b}}$ & $0.99(0.91,1.06)$ & 0.696 & $0.97(0.90,1.05)$ & 0.512 \\
\hline Work history $^{\mathrm{c}}$ & $1.10(1.05,1.14)$ & $<0.001$ & $1.08(1.03,1.13)$ & $<0.001$ \\
\hline WHPD $^{d}$ & $1.14(1.02,1.27)$ & 0.023 & $1.11(0.98,1.26)$ & 0.095 \\
\hline WDPW $^{\mathrm{e}}$ & $0.77(0.62,0.97)$ & 0.024 & $0.73(0.57,0.94)$ & 0.013 \\
\hline Sleep duration $^{b}$ & $0.85(0.71,1.1)$ & 0.069 & $0.83(0.69,0.99)$ & 0.050 \\
\hline SRF $^{b}$ & $1.00(0.99,1.01)$ & 0.599 & $1.00(0.99,1.01)$ & 0.779 \\
\hline
\end{tabular}

Abbreviations: OR: odds ratio; $\mathrm{Cl}$ : confidence interval; BMI: body mass index; WHPD: work

hours per day, WDPW: work days per week; SRF: self-reported fatigue.

a WHPD, WDPW, sleep duration, and economic status

b WHPD, WDPW, sleep duration, economic status, and age

c WHPD, WDPW, sleep duration, economic status, and education levels

dWDPW, sleep duration, economic status, and age

e WHPD, sleep duration, economic status, and age

An association is significant at $p$-value $<0.05$. 


\section{Discussion}

One of the objectives of this study was to determine the prevalence of HTN among Iranian taxi drivers, which had not been investigated in the past. It was observed that the prevalence of HTN was significantly high among Iranian taxi drivers. Accordingly, more than half of the participants suffered from HTN (59.8\%). In this study, a higher prevalence of HTN was observed than in previous published studies that reported the prevalence of HTN within the range of $18.2 \%$ and $57 \%$ [8, 27, 29$30,38-41]$. Furthermore, the comparison of the results of the present study with other studies that investigated the prevalence of HTN among other professional drivers, including suburban, bus, and truck drivers, showed that the prevalence of HTN was significantly higher in taxi drivers than in other professional drivers [28, 32-33, 42-46]. There are several reasons for the higher prevalence of HTN among taxi drivers, among which one could refer to simultaneous exposure to several risk factors, such as a sedentary lifestyle, an unhealthy diet plan, irregular work schedules [8-10], as well as external stressors, such as noise [11], vibration [12], air pollution [13, 14], and toxic vehicle exhaust emissions [15].

Another purpose of this study was to determine the factors probably playing a significant role in the prevalence of HTN among taxi drivers. To this end, we collected data from different lifestyle, medical, and work-related factors and used them in the multiple logistic regression models to examine the association between these factors and HTN. According to the results, a one-year increase in the participants' age significantly increased the risk of HTN by $4 \%$. According to the categorical analysis, subjects aged $\geq 45$ had a significantly higher risk of $68 \%$ in HTN than subjects aged < 45. These findings were similar to those of most previous studies on professional drivers [30, 33-35, 41, 43]. However, some studies show no significant association between the drivers' age and the prevalence of HTN $[36,38]$. Nevertheless, aging is a well-established risk factor for HTN. Aging, through several biological pathways, including inflammation, oxidative stress, and endothelial dysfunction, could lead to an increased risk of HTN [47]. In this study, a significant association was established between work history and HTN. Accordingly, there was a higher risk of HTN by $\% 8$, per one year increase in work history. Besides, the risk of HTN increased significantly by $120 \%$ in the subjects with work history $\geq 5$ years versus work history $<5$ years. This finding was in line with previous studies that reported an increased risk of HTN with a rise in work history [27, 30, 34, 41, 43].
It is worth noting that due to the high correlation between age and work history, the variable of age played an interfering role in the association.

In addition, we investigated several work-related risk factors, including WDPW, WHPD, SRF, and sleep duration. According to the findings from this research, taxi drivers working more than 10 hours per day were 2.64 times more at the risk of HTN than the reference group (workers who worked 8 hours and less per day). In addition, there was a significantly higher risk of HTN upon an hour increase in WHPD (at p-value $<0.10$ ), which was due to long sedentary times and less physical activities among the drivers. It is well established that low levels of physical activity or long sedentary times could significantly raise the risk of HTN. Moreover, taxi drivers working more hours per day could be more exposed to other parameters associated with HTN. According to some studies, exposure to traffic noise and air pollution could significantly raise the risk of HTN as well. In addition, drivers working more than 10 hours per day reported shorter sleep durations per night than drivers working 9-10 hours per day (6.4 vs.7.2 h) as well as drivers who worked eight hours and less per day (6.4 vs. $7.1 \mathrm{~h}$ ). Short sleep durations could be associated with a higher risk of HTN. In addition, a meta-analysis reported a significant dose-response relationship between sleep duration and HTN [26].

Interestingly, we noticed a lower risk of HTN (45\%) in the drivers working all days per week than the workers who had at least one day off. In contrast, upon a one-day increase in the working days, the risk of HTN decreased by $27 \%$. Although the two groups had no significant differences in age, BMI, SRF, and sleep duration, the drivers working all days per week had averagely 2 years of lower work history than the other group. In this study, the participants' sleep durations were examined as well, according to which, there was no significant association between the study groups in terms of sleep duration. In addition, it was observed that upon a one-hour increase in sleep duration, the risk of HTN significantly declined by $17 \%$. A previous meta-analysis reported a significant doseresponse relationship between sleep duration and HTN [26]. However, no significant association was observed between SRF status and prevalence of HTN among taxi drivers in this study.

In terms of lifestyle factors, a significant association was observed among marital status, economic status ( $p$-value $<0.05$ ), and education levels ( $p$-value $<0.10$ ). In addition, married taxi drivers were shown to be 2.57 times more than others at the risk of HTN, which was consistent with some previous studies [30, 33]. Accordingly, 
this finding could be due to the higher mean age (46.4 vs. 29.5), longer work history (8.1 vs. 2.7), and higher BMI (25.2 vs. 24.3) in the married drivers than in the single ones. However, some studies did not show a significant association between marital status and HTN [38, 43]. In terms of the variable of economic status, there was a higher risk of $\mathrm{HTN}$ by $72 \%$ in the drivers who reported poor economic status than in the reference group. This finding was consistent with a study that investigated this relationship among bus drivers in India [43]. However, it was inconsistent with other studies that showed no significant difference between hypertensive and nonhypertensive drivers in terms of economic status $[30,33,34]$. It was also observed, in this study, that drivers with lower educational levels (high school diplomas and less) had a significantly higher risk of $\mathrm{HTN}$ (by 73\%) than subjects with university diplomas, at the significance level of $p<0.10$. This finding was consistent with a study conducted on 491 taxi drivers in Brazil [41]. Although some studies did not show a significant association between educational levels and HTN [33, 34, 43], a recent meta-analysis reported that lower educational levels, as an independent risk factor, increased the risk of HTN (pooled OR= 2.02 and $95 \% \mathrm{Cl}=1.55-2.63$ ) [49]. In the present study, no significant association was found between the variables of BMI, smoking habit, physical activity, medical history, and HTN. These findings were similar to the previous studies on BMI [36], smoking habits [30, 33-36, 50], physical activity [33, 38, 50], medical history and HTN [36], diabetes [33, 36], family HTN [33], and family diabetes [33].

This study was faced with several limitations. Therefore, the results should be interpreted cautiously. Firstly, a cross-sectional design has some limitations in showing cause-effect relationships. Secondly, the use of a convenience sampling method with 321 drivers is not representative of the entire taxi driver population. Thirdly, we were not able to investigate the participants' diet plans. Finally, some of the variables in the present study, including sleep duration and SRF, were collected by subjective methods that could have been associated with measurement errors.

\section{Conclusion}

This study was the first attempt to determine the prevalence of HTN among Iranian taxi drivers. In addition, it was a unique attempt to identify risk factors playing a significant role in the prevalence of HTN in the taxi drivers. The findings obtained consider taxi drivers as a high-risk group in terms of HTN. Besides, it was demonstrated that the variables of age, work history, WHPD, WDPW, sleep duration, economic status, and education level could be significantly associated with the prevalence of HTN among taxi drivers. More studies are required, especially longitudinal ones, to confirm the present study findings and to overcome the mentioned limitations.

\section{Acknowledgement}

The authors of the present study would like to appreciate the participants involved in this study.

Conflict of interest: None declared.

\section{References}

1. Kearney PM, Whelton M, Reynolds K, Muntner $\mathrm{P}$, Whelton $\mathrm{PK}, \mathrm{He} \mathrm{J}$. Global burden of hypertension: analysis of worldwide data. lancet 2005; 365(9455):217-23.

2. Borzecki AM, Kader B, Berlowitz DR. The epidemiology and management of severe hypertension. J Hum Hypertens 2010; 24(1):918.

3. Lawes CM, Vander Hoorn S, Rodgers A; International Society of Hypertension. Global burden of blood-pressure-related disease, 2001. Lancet 2008; 371(9623):1513-8.

4. GBD 2013 Mortality and Causes of Death Collaborators. Global, regional, and national age-sex specific all-cause and cause-specific mortality for 240 causes of death, 1990-2013: a systematic analysis for the Global Burden of Disease Study 2013. Lancet 2015; 385(9963):117-71.

5. GBD 2017 Causes of Death Collaborators. Global, regional, and national age-sex-specific mortality for 282 causes of death in 195 countries and territories, 1980-2017: a systematic analysis for the Global Burden of Disease Study 2017. Lancet 2018; 392(10159):1736-88.

6. Lim SS, Vos $T$, Flaxman AD, Danaei G, Shibuya K, Adair-Rohani H, et al. A comparative risk assessment of burden of disease and injury attributable to 67 risk factors and risk factor clusters in 21 regions, 1990-2010: a systematic analysis for the Global Burden of Disease Study 2010. lancet 2012; 380(9859):2224-60.

7. GBD 2017 Disease and Injury Incidence and Prevalence Collaborators. Global, regional, and national incidence, prevalence, and years lived with disability for 354 diseases and injuries for 195 countries and territories, 1990-2017: a systematic analysis for the Global Burden of Disease Study 2017. Lancet 2018; 392(10159):1789-858.

8. Apantaku-Onayemi F, Baldyga W, Amuwo S, Adefuye A, Mason T, Mitchell R, et al. Driving to 
better health: cancer and cardiovascular risk assessment among taxi cab operators in Chicago. J Health Care Poor Underserved 2012; 23(2):768-80.

9. Burgel BJ, Gillen M, White MC. Health and safety strategies of urban taxi drivers. J Urban Health 2012; 89(4):717-22.

10. Gany FM, Gill PP, Ahmed A, Acharya S, Leng J. "Every disease ... man can get can start in this cab": focus groups to identify south Asian taxi drivers' knowledge, attitudes and beliefs about cardiovascular disease and its risks. J Immigr Minor Health 2013; 15(5):986-92.

11. Bruno PS, Marcos QR, Amanda C, Paulo ZH. Annoyance evaluation and the effect of noise on the health of bus drivers. Noise Health 2013; 15(66):301-6.

12. Funakoshi M, Taoda K, Tsujimura H, Nishiyama $\mathrm{K}$. Measurement of whole-body vibration in taxi drivers. J Occup Health 2004; 46(2):119-24.

13. Brucker N, Charão MF, Moro AM, Ferrari $P$, Bubols G, Sauer E, et al. Atherosclerotic process in taxi drivers occupationally exposed to air pollution and co-morbidities. Environ Res 2014; 131:31-8.

14. Wu S, Deng F, Niu J, Huang Q, Liu Y, Guo X. Association of heart rate variability in taxi drivers with marked changes in particulate air pollution in Beijing in 2008. Environ Health Perspect 2009; 118(1):87-91.

15. Zagury E, Le Moullec Y, Momas I. Exposure of Paris taxi drivers to automobile air pollutants within their vehicles. Occup Environ Med 2000; 57(6):406-10.

16. Hannerz $H$, Tüchsen $F$. Hospital admissions among male drivers in Denmark. Occup Environ Med 2001; 58(4):253-60.

17. Bigert C, Gustavsson P, Hallqvist J, Hogstedt C, Lewné $\mathrm{M}$, Plato $\mathrm{N}$, et al. Myocardial infarction among professional drivers. Epidemiology 2003; 14(3):333-9.

18. Tüchsen $\mathrm{F}$, Hannerz $\mathrm{H}$, Roepstorff $\mathrm{C}$, Krause N. Stroke among male professional drivers in Denmark, 1994-2003. Occup Environ Med 2006; 63(7):456-60.

19. Huang HY, Wang W, Zhou JP, Li QL, Feng WT, Wu ZZ. [Metabolic syndrome and its influencing factors in professional automobile drivers in a company]. Zhonghua Lao Dong Wei Sheng Zhi Ye Bing Za Zhi 2016; 34(4):258-61.

20. Izadi N, Malek M, Aminian O, Saraei M. Medical risk factors of diabetes mellitus among professional drivers. J Diabetes Metab Disord 2013; $12(1): 23$.

21. Mohebbi I, Saadat S, Aghassi M, Shekari M, Matinkhah M, Sehat S. Prevalence of metabolic syndrome in Iranian professional drivers: results from a population based study of 12,138 men. PloS One 2012; 7(2):e31790.

22. Siu SC, Wong KW, Lee KF, Lo YC, Wong $\mathrm{CH}$, Chan $\mathrm{AL}$, et al. Prevalence of undiagnosed diabetes mellitus and cardiovascular risk factors in Hong Kong professional drivers. Diabetes Res Clin Pract 2012; 96(1):60-7.

23. Hege A, Lemke MK, Apostolopoulos Y, Sonmez S. Occupational health disparities among U.S. long-haul truck drivers: the influence of work organization and sleep on cardiovascular and metabolic disease risk. PLoS One 2018; 13(11):e0207322.

24. Tabrizi R, Moosazadeh M, Razzaghi A, Akbari M, Heydari ST, Kavari SH, et al. Prevalence of sleep quality disorder among Iranian drivers: a systematic review and meta-analysis. J Inj Violence Res 2018; 10(1):53-9.

25. Meng L, Zheng Y, Hui R. The relationship of sleep duration and insomnia to risk of hypertension incidence: a meta-analysis of prospective cohort studies. Hypertens Res 2013; 36(11):985-95.

26. Li H, Ren Y, Wu Y, Zhao X. Correlation between sleep duration and hypertension: a dose-response meta-analysis. J Hum Hypertens 2019; 33(3):218-28.

27. Liu Z, Wang Y, Yan F, Wei X, Yu S. Analysis of risk factors for hypertension among taxi drivers on different shifts. Zhonghua Lao Dong Wei Sheng Zhi Ye Bing Za Zhi 2015; 33(4):263-5.

28. Shin SY, Lee CG, Song HS, Kim SH, Lee HS, Jung MS, et al. Cardiovascular disease risk of bus drivers in a city of Korea. Ann Occup Environ Med 2013; 25(1):34.

29. Elshatarat RA, Burgel BJ. Cardiovascular Risk Factors of Taxi Drivers. J Urban Health 2016; 93(3):589-606.

30. Adedokun AO, Ter Goon D, Owolabi EO, Adeniyi OV, Ajayi Al. Driving to Better Health: Screening for Hypertension and Associated Factors among Commercial Taxi Drivers in Buffalo City Metropolitan Municipality, South Africa. Open Public Health J 2017; 10(1):30312.

31. Persu A, Andries A, Demedts $S$, Van der Niepen $\mathrm{P}$, van de Borne $\mathrm{P}$, Belgian Hypertension Committee. Elevated prevalence of arterial hypertension amongst Belgian taxi drivers during the World Hypertension Day campaign 2006. J Hypertens 2006; 24(11):2311-12.

32. Cavagioni LC, Pierin AM, Batista KM, Bianchi ER, Costa AL. Health problems, arterial hypertension and predisposition to stress in truck drivers. USP School of Nursing Magazine 2009; 43(2):1267-71.

33. Lakshman A, Manikath N, Rahim A, Anilakumari VP. Prevalence and Risk Factors of Hypertension among Male Occupational Bus Drivers in North Kerala, South India: A CrossSectional Study. ISRN Prev Med 2014; 2014:318532.

34. Tobin EA, Ofili AN, Asogun DA, Igbinosun PO, Igba $K$, Idahosa A. Prevalence of hypertension and associated factors among inter-city drivers in an urban city in South-South Nigeria. Int $\mathrm{J}$ Res Med 2013; 2(3):5-12. 
35. Oyeniyi OS, Ajayi IO. Prevalence of hypertension and associated risk factor among interstate commercial drivers in Jabi Park Abuja. International Journal of Medicine and Medical Sciences 2016; 8(7):75-83.

36. Platek AE, Szymanski FM, Filipiak KJ, Kotkowski M, Rys A, Semczuk-Kaczmarek K, et al. Prevalence of Hypertension in Professional Drivers (from the RACER-ABPM Study). Am J Cardiol 2017; 120(10):1792-6.

37. Williams B, Mancia G, Spiering W, Agabiti Rosei E, Azizi M, Burnier M, et al. 2018 ESC/ESH Guidelines for the management of arterial hypertension: The Task Force for the management of arterial hypertension of the European Society of Cardiology (ESC) and the European Society of Hypertension (ESH). Eur Heart J 2018; 39(33):3021-104.

38. Gany F, Bari S, Gill P, Ramirez J, Ayash C, Loeb R, et al. Step On It! Workplace Cardiovascular Risk Assessment of New York City Yellow Taxi Drivers. J Immigr Minor Health 2016; 18(1):118-34.

39. Martin WP, Sharif F, Flaherty G. Lifestyle risk factors for cardiovascular disease and diabetic risk in a sedentary occupational group: the Galway taxi driver study. Ir J Med Sci 2016; 185(2):403-12.

40. Yang $Y$, Fan $X S$, Tian $\mathrm{CH}$, Zhang $\mathrm{W}$, Li J, Li $S Q$. Health status, intention to seek health examination, and participation in health education among taxi drivers in Jinan, China. Iran Red Crescent Med J 2014; 16(4):e13355.

41. Vieira MC, Sperandei S, Reis AC. Physical activity overcomes the effects of cumulative work time on hypertension prevalence among Brazilian taxi drivers. J Sports Med Phys
Fitness 2016; 56(5):631-8.

42. Khoshandam Sarvynehbaghi F, Mozaffari SAR, Yaghoubi Poor A, Nezamtabar Malekshah A. Prevalence of Hypertension among Professional Drivers in Mazandaran Province, 2010. Journal of Mazandaran University of Medical Sciences 2013; 23(102):19-24.

43. Borle AL, Jadhao A. Prevalence and associated factors of hypertension among occupational bus drivers in Nagpur City, Central India-A cross sectional study. Age (Years) 2015; 6:423-8.

44. Hirata RP, Sampaio LM, Leitão Filho FS, Braghiroli A, Balbi B, Romano S, et al. General characteristics and risk factors of cardiovascular disease among interstate bus drivers. ScientificWorldJournal 2012; 2012:216702.

45. dos Reis LAP, Costa CDD, Rodrigues DS, de Alcântara KC. Obesity, hypertension and diabetes among truck drivers in the middlewest, Brazil. Biosci J 2017; 33(2):485-93.

46. Saberi HR, Moravveji AR, Fakharian E, Kashani MM, Dehdashti AR. Prevalence of metabolic syndrome in bus and truck drivers in Kashan, Iran. Diabetol Metab Syndr 2011; 3(1):8.

47. Buford TW. Hypertension and aging. Ageing Res Rev 2016; 26:96-111.

48. Bawa MS, Srivastav M. Study the epidemiological profile of taxi drivers in the background of occupational environment, stress and personality characteristics. Indian J Occup Environ Med 2013; 17(3):108-13.

49. Leng $B$, Jin $Y, L i ~ G$, Chen $L$, Jin $N$. Socioeconomic status and hypertension: a meta-analysis. J Hypertens 2015; 33(2):221-9.

50. Satheesh B, Veena RM. A study of prevalence of hypertension among bus drivers in Bangalore City. Int J Curr Res Rev 2013; 5:90-4. 